\title{
The Study of Information Support System for Decision Making based on Kansei Engineering
}

\author{
A. Hadiana, A. A. Wahid, A. Sofyan, D. Hirawan, K. Patalia, and M. Z. Faruqi
}

\begin{abstract}
Kansei Engineering has been adopted as a method to analyze the relationship between human emotional factors and the critical elements design of system in developing a new product of software based on consumers' emotion. However, the general analysis in kansei engineering has been using statistical analysis such as principal component analysis, factor analysis etc. in evaluating the data average gathered from all respondents, and then giving a recommendation the suitable product. This paper reports an attempt to discover the relationship between interface design of product and consumers' emotion using Multiple Attribute Decision Making (MADM) method rather than using the convensional of statistical method. This research also recommends a global system design of kansei engineering system to support consumers' decision in choosing the most desired product based on their real emotional feeling.
\end{abstract}

Index Terms - Consumers, Decision Support System, Element Design, Emotion, Kansei Engineering, MADM.

\section{INTRODUCTION}

Consumers are the central points on shopping whether in online or real shopping. Sometime consumers face a condition that need decision to choose which one product they have to select based on their needs and their passion. But most of system online or traditional lacks of facility of supporting their decision in shopping, so consumers are still confused when they bought the product whether their decision is true or not.

Most of online shopping focuses on their system interface to facilitate the consumers. On the other hand, they are many kinds of products are delivered to the consumers, however the system lacks of supporting facility such as decision support system to buy the suitable thing they want based on their feeling or their emotion to the product. Kansei engineering is one kind of approach has been widely used in the research of product development based on the emotional feeling. Since, kansei engineering has an ability to translate consumers' psychological feeling into a concept of emotion that is proposed to be adopted into developing online shopping with decision support component.

Submitted on July 16, 2021

Published on August 06, 2021.

A. Hadiana, Research Center for Informatics - LIPI, STMIK-LIKMI Bandung, Indonesia.

(e-mail: anahadiana.p2i.lipi ${ }^{@}$ gmail.com)

A. A. Wahid, Information System Post Graduate Program, STMIK-LIKMI

Bandung, Indonesia.

(e-mail: aly.dihaw96@gmail.com)

A. Sofyan, Information System Post Graduate Program, STMIK-LIKMI

Bandung, Indonesia.

(e-mail: sofyan.wahyudin ${ }^{@}$ gmail.com)
This research aims to explore the relationships between consumers' emotional feeling (psychological factor) with product using combination of kansei engineering method and Multi Attribute Decision Method (MADM). The main target of this research is the general design of decision support system that could be used as guide of consumers during online shopping in making decision to buy a product based on the perspective of consumers' psychological or emotional requirements, so consumers will get what they desire, and use it for a long time in the future.

\section{RELATED WORKS}

Many researches have been conducted by adopting kansei engineering in diverse fields in product emotion including software systems. Some of past researches include emotion and entertainment [3], [4], emotion and wheel chair [5], emotion and e-commerce [6], [7], emotion and textile [8], [9], emotion and fashion design [10], etc.

There are many definitions of kansei, the founder of kansei engineering, Nagamachi, defines kansei as a state that implies psychological feeling and needs in mind [11]. Kansei is also referred to the state of mind where knowledge, emotion, and passion are harmonized [12]. Kansei engineering was established as a discipline that brilliantly assimilates kansei, psychology, engineering, and statistics [13]. The use of kansei engineering is targeted to enable development of products that win the heart and the mind of consumers. The methodology of kansei is a systematic process to discover insight of consumers' responses toward artifact via several physiological and psychological assessment methods. These knowledges will be translated into design elements, and then generate the formulation of a new product design that embeds consumers' implicit emotional feelings and desires. It is also an evident that kansei methodology can be used to enable attractive discussion in distance learning environment, as positive emotion has been found to positively associates with learning [14]-[18].

D. Hirawan, Faculty of Information Engineering, Universitas Komputer Indonesia (UNIKOM), Bandung, Indonesia.

(e-mail: dhirawan88@gmail.com)

K. Patalia, Universitas Islam Negeri Sunan Gunung Djati (UIN SGD), Bandung, Indonesia.

(e-mail: karina.patalia ${ }^{@}$ uinsgd.ac.id)

M. Z. Faruqi, Information System Post Graduate Program, STMIK LIKMI Bandung, Indonesia.

(e-mail: uqi.zulkhaidir ${ }^{@}$ gmail.com) 


\section{SYSTEM REQUIREMENTS}

This research tries to adopt MADM into kansei engineering method especially in order to make a decision to select the suitable one from many alternative objects. For example, in online shopping many consumers always feel confused to select a really desired thing. It is psychological problem which one to be selected. Unfortunately, this kind of function is not available in many online shopping systems to provide consumers more comfortable environment during shopping and buying what they need based on what they emotionally desire.

This system basically adopted the Kansei Engineering Method Type I (KE Pack) because it has simplicity and is also widely used in many kansei products development [2], [6], [10], [19], [20]-[23].

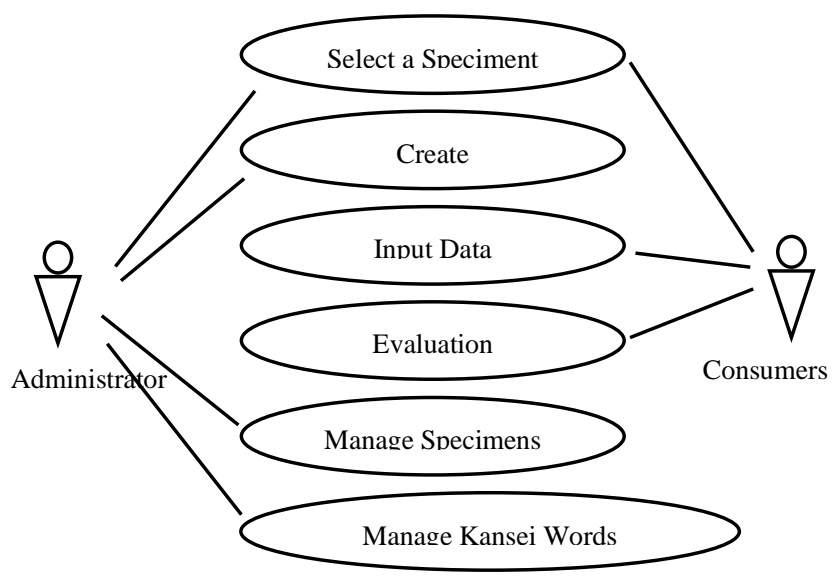

Fig. 1. Usecase Diagram.

Fig. 1 and Table I show the basic functional requirements to be fulfilled in development of this kansei engineering support system. Basically, this system requires six functions to perform kansei analysis based on MADM such as select specimen, create SD scale, input data, evaluation, manage specimens, and manage kansei words.

\section{TABLE I: USECASE DESCRIPTION}

\begin{tabular}{ll}
\hline \multicolumn{1}{c}{ Usecase Name } & \multicolumn{1}{c}{ Description } \\
\hline Select Specimens & $\begin{array}{l}\text { Select the specimens to be evaluated by } \\
\text { consumers according to elected kansei words } \\
\text { Create Questionnaire }\end{array}$ \\
Create a questionnaire table to be inputted by \\
consumers using the five points SD scale \\
Consumers enter the value from 1 to 5 point \\
for each specimen using data questionnaire \\
according to their emotional feelings. \\
Calculates the data of questionnaire and \\
calculates it's to get its average. Performs \\
MADM to evaluate specimens, and the finds \\
which product to be recommended as a \\
desired product. \\
Manage specimens stored in database \\
whether to add, to delete, to edit according to \\
the requirements \\
Manage which kansei words to be selected \\
and used for the evaluation
\end{tabular}

\section{SYSTEM GRAND DESIGN}

This kansei engineering support system in general consists of two structures, there are system structure and data structure.

\section{A. System Structure}

This system originally will be constructed based on client/server architecture and uses Model View Controller (MVC) framework.

The main elements included in this support system are described as follow:

1) Model - Data Collection

This is a module to collect three kinds of basic data such as specimens, kansei words, and data questionnaires from consumers.

2) Controller - Evaluation

This is a module to make many calculations such as average calculation of collected data from consumers, calculation using MADM based on average data, and sorting priorities.

7View-Display Decision

This is a module of interface for collecting data and showing the calculation's result to consumers. There are two kinds of interface for users such as for administrator, consumers. Users connect to the system through its interface on web browser.

Fig. 2 shows the basic structure of our web based kansei engineering support system that divided into server side and client side.

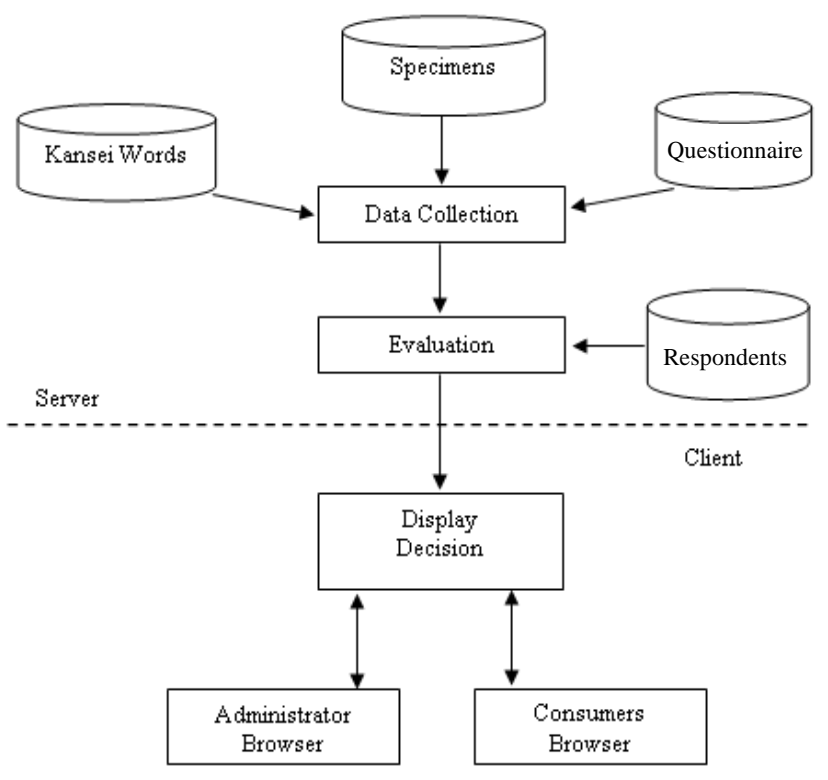

Fig. 2. The Structure of KE Support System.

The evaluation module in this system uses method of MADM such as TOPSIS (Technique for Others Preference by Similarity to Ideal Solution), AHP (Analytical Hierarchy Process) etc. However, in this research TOPSIS is considered more potential and more precision to make a decision by calculating gathered data from respondents according to the following processes [24]:

1) Making a normalized decision matrix using all averages of data questionnaire.

2) Performing weighted calculation to the normalized 
decision matrix.

3) Deciding ideal positive solution matrix and negative solution matrix.

4) Determining the distance between the value of each specimen with positive ideal solution matrix and negative ideal solution matrix.

5) Determining the preferential value for each specimen with each rank.

\section{B. Data Structure}

This system consists of several data entities to perform consumers' emotions using kansei engineering and MADM. Fig. 3 describes the entity relationship diagram that shows required data and manage it in this system.

There are at least five main data entities to store all required data in calculating using this kansei engineering support system as follows.

\section{1) Specimens}

Specimens are the samples that will showed to consumers to evaluate it according to their feelings. The data of all specimens are collected and shown to consumers during the questionnaire.

2) Kansei words

The alternative kansei words are adjectives or sentences that are considered sufficient to represent what consumers feel about product. Kansei words consist of all specific words related to specimens according to consumers emotional feeling.

3) Questionnaire

This data consists of the combination of specimens and kansei words using five points semantic differential scale. This data will be evaluated to find the grade of consumers' emotional feeling after exploring the specimens.

4) Respondents

Respondents are the consumers who participate in entering the questionnaire and will use this system. They are required to input the data of questionnaire for every specimen by entering the five points semantic differential of each kansei words according to their emotional preferences.

5) Result

The collected data from questionnaire, will be calculated to find all averages of each kansei words per specimens. The system then will evaluate all data. First calculating all data's averages, and then calculate them using the method of MADM to get the ranks of all specimens and make a decision for selecting the suitable specimen. The result data will be visualized using diagram, so consumers is easier to understand the result of calculation.

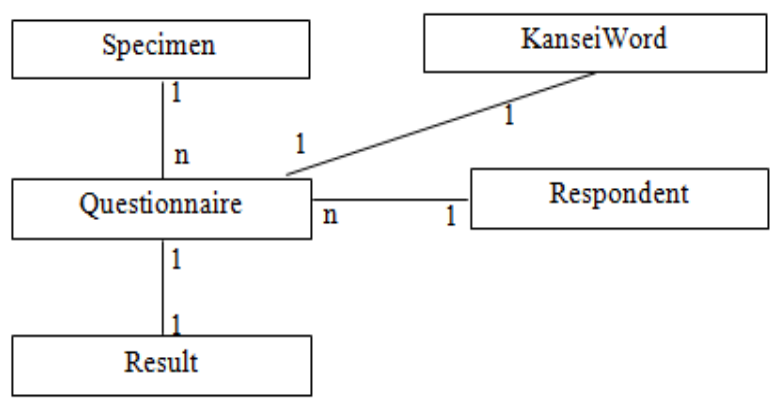

Fig. 3. Relationship Diagram.
Table II shows main attributes of each etities including the main attribute as Primary Key (PK). Using these entities all necessary data are stored. The collected data also can be reused many times for the future analysis in order to resume all data from consumer's emotional feelings. In the real implementation, this system must require more entities to store the data.

TABLE II: DATA STRUCTURE

\begin{tabular}{ll}
\hline \hline \multicolumn{1}{c}{ Entity Name } & \multicolumn{1}{c}{ Attributes } \\
\hline Specimens & ID_Specimen(char - PK), Name \\
& (varchar), Figure (image) \\
Kansei Words & ID_KW (char - PK), Name (varchar), \\
& Description (varchar) \\
Questionnaire & ID_SD (char - PK), ID_KW (char - \\
& PK), Value (numeric) \\
Respondents & ID_Respondent (char - PK), Fullname \\
& (varchar), Sex (boolean) \\
Result & ID_Result (char - PK), Calculation \\
& (numeric), Decision (char) \\
\hline \hline
\end{tabular}

All data will be stored in database server that separated from web server. It is benefited to reduce server load and keep the best performance, especially when many consumers try to access the system at the same time.

Table III shows all open source software that will be used as main software's components for implementing this support system.

TABLE III: SYSTEM STRUCTURE

\begin{tabular}{cc}
\hline \hline Component & Software \\
\hline Web Server & Apache HTTP Server \\
Database Server & PostgreSQL Server \\
Operating System & Linux Debian \\
\hline \hline
\end{tabular}

\section{CONCLUSION}

Kansei engineering has been adopted in this research to analyze consumers' preferences based on psychological factors. In this research, emotional aspects are considered as the variable of MADM in calculating data questionnaire to get a suitable decision.

This web based kansei engineering support system can be implemented to support consumers when they face the condition to select the suitable thing in shopping according to the emotional preferences. The implementation of MADM in kansei engineering can be used for varieties objects as specimens.

For further research it is important to explore the specification and the design of system in more detail and continue the system development based on this result. This system has to provide many kinds of access facilities from client to server not only using desktop, but also smartphone, in order to widen system's accessibility.

Considering giving more alternative decisions for consumers is important. Therefore, all methods of MADM including TOPSIS are better to be included in the next system development.

\section{ACKNOWLEDGMENT}

The authors would like to thank all graduate students of Information System Post Graduate Program of STMIK 
LIKMI Bandung for their great supporting in discussion and cooperation during this research. The authors also would like to thank Research Center for Informatics (P2I) - Indonesian Sciences of Instititute (LIPI) for its great support and donation in this research.

\section{REFERENCES}

[1] J. Prihati, Mustafid, Suhartono, Penerapan, "Model Human Computer Interaction (HCI) dalam Analisis Sistem Informasi", (Studi Kasus SAS Dikmeni DKI Jakarta), Universitas Diponegoro, Semarang, 2009.

[2] A. M. Lokman, L. M. Noor, and M. Nagamachi, "ExpertKanseiWeb: A tool to design Kansei website", Enterprise Information Systems. Lecture Notes in Business Information Processing (LNBIP), 2009, Vol. 24, pp. 894-905.

[3] N. Sato, M. Anse, and T. Tabe, "A method for constructing a movieselection support system based on Kansei Engineering." In The 12th International Conference on Human-Computer Interaction (HCII). Beijing, 2007.

[4] T. Kodai, and T. Onisawa, "Generation of Scene Frame of Manga from Narrative Text", International Conference on Kansei Engineeering and Emotion Research (KEER), Paris, 2010.

[5] M. N. Ismail, A. M. Lokman, and N. A. S. Abdullah, Formulating Kansei Concepts of Assistive Device for People with Physical Disabilities, 3rd International Conference on User Science and Engineering (i-USEr), Shah Alam, 2014.

[6] A.M. Lokman., Emotional User Experience in Web Design: The Kansei Engineering Approach (A PhD Thesis). [Online] Available: www.anitawati.uitm.edu.my, 2009.

[7] K. Wang, and T. Wang, "Applying Kansei Engineering on the ecommerce web of $3 \mathrm{C}$ product." In Kansei Engineering and Emotion Research International Conference (KEER2010). Paris.

[8] N. Shaari, F. Terauchi, M. Kubo, and H. Aoki, Recognizing Female's Sensibility in Assessing Traditional Clothes.", The 6th Asian Design Conference, 2003.

[9] T. Ogawa, Y. Nagai, and M. Ikeda, "An ontological approach to designers' idea explanation style: Towards supporting the sharing of Kansei-ideas in textile design." Advanced Engineering Informatics 23:157-164, 2009

[10] A. M. Lokman, and A. A. Aziz, A Kansei system to support children's clothing design in Malaysia, IEEE International Conference on Systems Man and Cybernetics (SMC), Istanbul, 2010.

[11] A. M. Lokman, and M. Nagamachi, Kansei Engineering - A Beginner Perspective. 1st Edition, Selangor, Malaysia: UPENA, Shah Alam, 2010.

[12] M. Nagamachi, and A.M. Lokman, Innovations of Kansei Engineering Industrial Innovation Series. Adedeji B. Badiru (Eds.), Taylor \& Francis Group, Florida, 2011.

[13] M. Nagamachi, and A. M. Lokman, Kansei Innovation: Practical Design Applications for Product and Service Development. Taylor \& Francis Group, 2015.

[14] F. Redzuan, A. M. Lokman, Z. A. Othman, and S. Abdullah, "Kansei Design Model for E-Learning: A Preliminary Finding", Proceeding of the 10th European Conference on e-Learning (ECEL-2011), Brighton, 2011.

[15] F. Liu, "Personalized Learning Using Adapted Content Modality Design for Science Students", Paper read at ECCE Conference, London, UK. August, 2007.

[16] K. G. D. Tharangie, C. M. A. Irfan, C. A. Marasinghe, and K. Yamada, "Kansei engineering assessing system to enhance the usability in Elearning web interfaces: Color basis", In Workshop Proc. 16th Inter Conf. on Computers in Education( ICCE), Workshop on Testing and Assessment, Taipei, 2008.

[17] H. T. Chaminda, A. Basnayake, A. Madurapperuma, and M. Osano, "An interactive E-Learning system using Kansei engineering", In International Conference on Biometrics and Kansei Engineering (pp. 157-162), 2009.

[18] T. C. Sandanayake, and A. P. Madurapperuma, "Conceptual model for E-Learning systems using Kansei Engineering techniques", In International Conference on Biometrics and Kansei Engineerin, pp. 148-152, 2009.

[19] F. Redzuan, A. M. Lokman, and Z. A. Othman, "Kansei semantic space for emotion in online learning", 3rd International Conference on User Science and Engineering (i-USEr), Shah Alam, 2014.

[20] N. F. Taharim, A. M. Lokman, W. A. R. W. M. Isa, and N. L. M. Noor, "A Theoretical Framework of Playful Interaction in Mobile Learning",
Eighth International Conference on Next Generation Mobile Apps, Services and Technologies (NGMAST), Oxford, 2014.

[21] Y. Chen, "Reseach on Optimized Design of Kansei Engineering-based Web Interface", International Conference on Computational and Information Science, 2013.

[22] A. M. Lokman, and S. N. Hussin, "Kansei website interface design: Practicality and accuracy of Kansei Web Design Guideline", 2nd International Conference on User Science and Engineering (i-USEr) 2011

[23] A.M. Lokman, M.B.C. Haron, S.Z.Z. Abidin, N.E.Z. Khalid, and S Ishihara, Prelude to Natphoric Kansei Engineering Framework, Journal of Software Engineering and Applications, Vol. 6, 2013 pp. 638-644.

[24] Kusumadewi, Sri, et all., Fuzzy Multi-Atribute Decision Making,

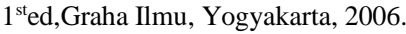

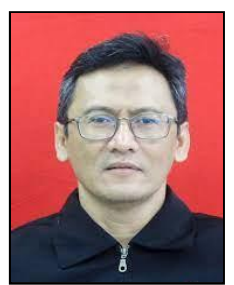

A. Hadiana was born in 1968. His majority research is kansei engineering, software engineering, human computer interface, data mining, distance learning, and enterprise architecture.

He worked as post-doctoral researcher at National Institute for Informatics (NII) - Japan for one year in 2005-2006. He is working as researcher at Research Center for Informatics - LIPI Indonesia, and also is working as senior lecturer at Post Graduate Program STMIK-LIKMI Bandung - Indonesia. He graduated B. Eng, M. Eng from Faculty of Information Engineering Fukui Univerisity - Japan in 1993, 1995 respectively, and graduated Dr. Eng from Faculty of Information Engineering - Shinsyu University Japan in 2004

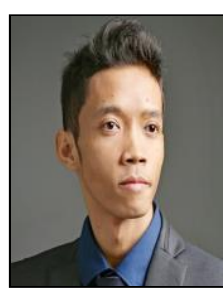

A. A. Wahid was born in 1996. His majority research is kansei engineering, software engineering, database, human computer interface and enterprise architecture.

$\mathrm{He}$ is working as software engineer and graduated undergraduate program of information science from Politeknik Pos Bandung Indonesia 2018. He is studying at Post Graduate Program of Information System - STIMIK-LIKMI Bandung, Indonesia.

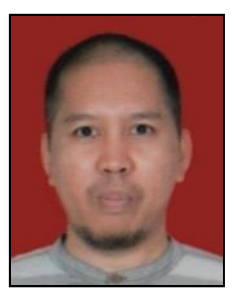

A. Sofyan was born in 1985 . His majority research is kansei engineering, information system, database, human computer interface and enterprise architecture.

$\mathrm{He}$ is working as software engineer and graduated undergraduate program of information engineering from STMIK Mardira Indonesia in 2009. He is studying at Post Graduate Program of Information System - STIMIK-LIKMI Bandung, Indonesia.

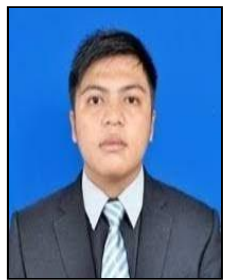

D. Hirawan was born in 1986. His majority research is image processing, information system, software engineering, human computer interface and machine learning.

$\mathrm{He}$ is working as lecturer in Faculty of Information Engineering of Universitas Komputer Indonesia (UNIKOM). He graduated S.Kom from Information Engineering Undergraduate Program UNIKOM and M.Kom from Information System Post Graduate Program from UNIKOM in 2014 and 2018 respectively. He is continuing the study at Doctoral Program of Computer Science - Institut Pertanian Bogor (IPB) Bogor - Indonesia.

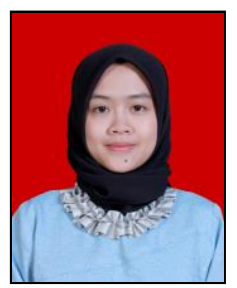

K. Patalia was born in 1992. Her recent majority research mainly is in field of data mining, behavioural of information system, kansei engineering, enterprise architecture, and project \& change management of information system She is working as lecturer at Universitas Negeri Islam - Sunan Gunung Djati (UIN-SGD) Bandung Indonesia. She graduated from undergraduate program of information engineering - UIN-SGD Indonesia in 2014. She is studying at Post Graduate Program of Information System - STIMIK-LIKMI Bandung. 


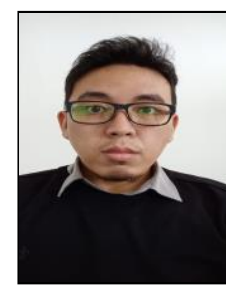

M. Z. Faruqi was born in 1990 . His majority research is information system, kansei engineering, database, enterprise architecture, and human computer interface.

He is working as software engineer and graduated undergraduate program of information engineering from Universitas Komputer Indonesia (UNIKOM) in 2013. He is studying at Post Graduate Program of Information System - STIMIK-LIKMI Bandung, Indonesia. 